\title{
Evaluasi Pengembangan UMKM Kabupaten Rokan Hulu Menggunakan Busines Model Canvas
}

\author{
PURWANTORO \\ Fakultas Ekonomi Universitas Pasir Pengaraian \\ Jln. Tuanku Tambusai, Desa Kumu, Rambah Hilir \\ E-mail : purwan78@gmail.com
}

\begin{abstract}
Micro Small medium enterprises (UMKM) in each state specifically in the ASEAN region faced with the situation of global competition. A very tight competition is forcing businessmen to become the best. One of the ways that it can be reached by the trade to be able to be the best business strategy is appropriate, effective and efficient. This research aims to find out how the application business model canvas in creating alternative business strategies for the development of UMKM. The second objective is to know the proper strategic alternatives for the development of UMKM. The methods used in this research is descriptive qualitative approach with the use of informants as respondents research. The data source used is the business owners as much as 16 UMKM who open businesses in the downtown area of Pasir Pengaraian. Data collection techniques using interview techniques directly, observation and documentation. This research uses a template business model canvas to map strategy for the effort and combined with the SWOT analysis. Based on data obtained from the results of research, that the description of the business model approach UMKM using Business Model Canvas outline can be used as recommendations for business strategy, the business model which is currently already underway is able to meet the Nine elements of the blocks on the template business model canvas. The findings of this research are that not all the UMKM business strategy and have just run a business without the vision of enterprise development. Based on the results of the SWOT analysis can be found that alternative new efforts by optimizing internal strength in revenue streams on each UMKM and conduct elections to the right customer segments. Suggestions that may the researcher pointed out every UMKM should be more daring to have the vision to grow and continue to innovate against products goods or services, increase customer segmentation and make use of business model canvas approach in making the strategy of the business.
\end{abstract}

Keywords: Business Model Canvas, UMKM, Business Strategy, Rokan Hulu, Competition

Usaha Kecil Menengah (UMKM) pada setiap negara khususnya di wilayah Asean dihadapkan pada situasi persaingan global yang ketat. Persaingan yang sangat ketat ini memaksa perusahaan untuk menjadi yang paling baik dari yang terbaik untuk dapat bertahan di era globalisasi ini. Pada tahun 2016 jumlah wirausaha Indonesia masih sekitar $3,1 \%$ dari total jumlah penduduk artinya hanya $2 \%$ dari total penduduk indonesia. Bila dibandingkan dengan negara-negara Asia Tenggara dan negara maju lain jumlah ini masih jauh tertinggal. Ratio wirausaha sebesar 3,1 persen itu masih lebih rendah dibandingkan dengan negara lain seperti Malaysia 5\%,
China 10\%, Singapura 7\%, Jepang $11 \%$ maupun AS yang $12 \%$.

Rokan Hulu merupakan daerah yang memiliki potensi ekonomi yang baik seiring dengan perkembangan dan pembangunan dari semua sektor tetapi tidak sejalan dengan perkembangan UMKM di Rokan Hulu yang mengalami pertumbuhan yang stagnan, dimana saat ini terdapat 36.044 pelaku usaha UMKM (kumkm.riau.go.id) dan hanya menempati urutan ke posisi 8 dari 12 Kabupaten yang ada di Provinsi Riau. Melihat gejala ini maka sangat diperlukan suatu gebrakan untuk meningkatkan gairah wirausaha, dimana saat ini Rokan Hulu menjadi daerah destinasi wisata baru. Ada 
beberapa kebijakan yang telah dilaksanakan oleh Pemerintah khususnya Provinsi Riau yang berperan dalam perkembangan dan pertumbuhan UMKM di Provinsi Riau secara umum diantaranya:

1. Mengadakan program pembinaan usaha, dan kemampuan dalam penguasaan teknologi bagi pengusaha, dan relokasi industri.

2. Melalui Badan Penelitian dan Pengembangan (BPP) Riau telah menyiapkan generasi muda untuk dibina, dalam bentuk kerja sama dengan satuan kerja di tingkat kabupaten/kota, Dinas Tenaga kerja, Dinas Pariwisata, Dinas Perindustrian dan Perdagangan dan Dinas-dinas lainnya yang terkait.

3. PNM sebagai BUMN memberikan jasa pembiayaan atau permodalan, dan juga jasa manajemen (capacity building )sehingga bisa menopang kualitas jasa pembiayaan.

4. Penghargaan terhadap insan kreatif melalui Anugerah Sagang tiap tahunnya.

Permasalahan dilapangan yang terdapat di Kabupaten Rokan Hulu disebabkan beberapa faktor yang mengakibatkan menurunnya jumlah UMKM yang ada di Kabupaten Rokan Hulu antara lain:

1. UMKM tidak mampu melakukan efisiensi terhadap kegiatan operasinya, sehingga berhenti beroperasi,

2. Banyak UMKM memindahkan tokonya kedaerah lain guna mencari peluang

3. Sebagian UMKM tidak mampu bertahan dalam persaingan di pasar, sehingga berimplikasi pada menurunnya kinerja yang dicapai setiap perusahaan

Upaya menyelesaikan

permasalahan yang dihadapi oleh UMKM yang berada di Kabupaten khususnya di Kabupaten Rokan Hulu perlu adanya analisis usaha dengan menggunakan Business Model Canvas (BMC) karena analisis ini mampu menjelaskan secara menyeluruh baik dari segi pemasaran, sumber daya manusia, keuangan, sampai dengan nilai atau produk yang ditawarkan. Sehingga pengusaha bisa menentukan arah bergerak bagi perusahaan serta mengetahui keunggulan bersaing yang ada pada bisnis yang sedang dijalankannya. sebuah model bisnis sangat diperlukan untuk menggambarkan dasar pemikiran tentang bagaimana organisasi menciptakan, memberikan, dan menangkap nilai. Artinya dapat kita pahami bahwa sebuah organisasi bisnis yang ingin sukses dan mampu mengembangkan usahanya haruslah menciptakan, memberikan dan menangkap nilai yang berkaitan dengan aktivitas organisasi bisnisnya, tidak terkecuali dengan organisasi bisnis UMKM. Untuk memajukan usaha, UMKM harus memahami bagaimana sesungguhnya menciptakan nilai-nilai terbaik kepada konsumen yang ingin dijangkaunya, supaya menjalankan kegiatan usahanya mendapatkan kepercayaan dari para konsumen karena telah memberikan nilai-nilai terbaik. Penerapan bussines model canvas telah dilakukan oleh beberapa penelitian sebelumnya bahwa menurut Osterwalder dan pigneur (2012:14) mengatakan bahwa model bisnis dapat dijelaskan dengan sangat baik melalui sembilan blok bangunan dasar yang memperlihatkan cara berfikir tentang bagaimana cara perusahaan menghasilkan uang. Sembilan blok bangunan tersebut adalah Business Model Canvas yang tersusun dalam sebuah susunan yang satu-kesatuan. Business Model Canvas terdiri dari sembilan blok bangunan yaitu: Customer Segments (Segmen Pelanggan), Value Propositions (Proporsi Nilai), Channels (Saluran), Customer Relationship (Hubungan Pelanggan), Revenue Streams (Arus Pendapatan), Key Resources (Sumber Daya Utama), Key Activities (Aktivitas Kunci), Key Partnership (Kemitraan Utama), Cost Structure 
(Struktur Biaya). Bagian-bagian tersebut kemudian dipetakan menjadi 2 sisi yaitu sisi kanan (kreativitas) dan kiri (logika). Aktivitas-aktivitas bisnis yang dilakukan baik usaha besar maupun usaha kecil secara tidak langsung telah menerapkan business model canvas didalam menjalankan kegiatan bisnisnya, meskipun dalam penerapannya hanya menggunakan beberapa blok dari sembilan blok bangunan.

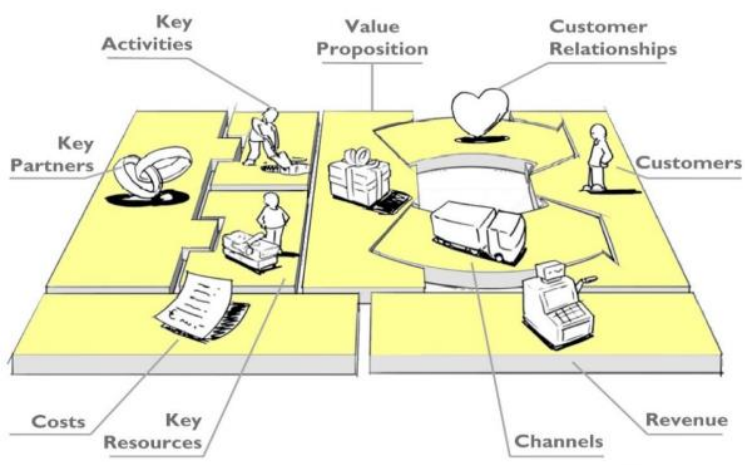

Sumber : Osterwalder \& Yves Pigneur (2012:19)

Penelitian lain juga menjelekaskan bahwa Business Model Canvas dapat menjadi tools yang sederhana guna menghasilkan alternatif strategi perusahaan yang berujung pada kelayakan finansial (Dewobroto, 2013). Hal yang sama disampaikan oleh (Tjitradi, 2015) yang dalam penelitiannya menyatakan bahwa Bussines Model Canvas adalah sebuah model bisnis yang dapat dijadikan bahan evaluasi dan perancangan sebuah model bisnis baru yang lebih baik dan modern bagi usaha yang sedang dijalankan dimasa depan. Pemikiran yang sama juga disampaikan oleh (Boedianto dan Harjati, 2015) menyatakan business model canvas dapat digunakan sebagai pendekatan untuk menciptakan strategi pengembangan bisnis. Model business yang baik selalu memperhatikan tentang nilai pelanggan, hubungan pelanggan, segmen pelanggan, serta selalu mengedepankan penerapan teknologi yang lebih modern untuk menciptakan kepuasan kepada pelanggan (Stefan dan Richard, 2014). Selain itu
(Putri, 2015) menyatakan penggunaan pendekatan BMC dapat memberikan peluang usaha yang lebih besar untuk pengembangan usaha dengan analisis SWOT pengusaha dapat mengetahui ancaman yang dihadapi. Penelitian ini bertujuan untuk mencari alternative strategi usaha baru yang mengaplikasikan model bussines canvas serta untuk memetakan UMKM yang ada di Kabupaten Rokan Hulu.

Penelitian ini menggunakan elemen-elemen Business model canvas untuk mengidentifikasi dan menemukan elemen yang terjadi pada UMKM di Kabupaten Rokan Hulu. Setelah mengidentifkasi elemen BMC, peneliti menganalisis SWOT dari UMKM yang bertujuan untuk membuat peta kekuatan internal dan external dari usaha tersebut. Alasan digunakan analisis SWOT dalam penelitian ini adalah karena menurut Kurtz $(2008,45)$ SWOT analisis adalah suatu alat perencanaan strategik yang penting untuk membantu perencana untuk membandingkan kekuatan dan kelemahan internal organisasi dengan kesempatan dan ancaman dari external sedangkan Pearce and Robinson $(2007,134)$ analisis SWOT perlu dilakukan karena analisa SWOT untuk mencocokkan fit antara sumber daya internal dan situasi eksternal perusahaan. Pencocokkan yang baik akan memaksimalkan kekuatan dan peluang perusahaan dan meminimumkan kelemahan dan ancamannya. Asumsi sederhana ini mempunyai implikasi yang kuat untuk design strategi yang sukses. Ditambahkan lagi oleh Robert W.Duncan (2007, 142) menganalisa lingkungan internal dan eksternal merupakan hal penting dalam proses perencanaan strategi. Faktor-faktor lingkungan internal di dalam perusahaan biasanya dapat digolongkan sebagai Strength (S) atau Weakness (W) dan lingkungan eksternal perusahaan dapat diklasifikasikan sebagai Opportunities (O) atau Threat (T). Menurut Thompson $(2008,97)$ analisa SWOT adalah simpel tetapi merupakan 
alat bantu yang sangat kuat untuk memperbesar kapabilitas serta mengetahui ketidakefisienan sumber daya perusahaan serta kesempatan dari pasar dan ancaman eksternal untuk masa depan agar lebih baik lagi. Sedangkan alasan digunakan analisis elemen Business Model Canvas ( BMC ) pada penelitian ini adalah untuk mengetahui sejauh mana strategi yang telah digunakan oleh UMKM yang ada di Kabupaten Rokan Hulu. Sejauh ini penggunaan Business Model Canvas Hanya digunakan pada satu usaha saja, maka penelitian berinisiatif menggunakan business model canvas untuk memetakan strategi usaha UMKM yang di kombinasikan dnegan analsisi SWOT. Penelitian ini memiliki kerangka penelitian sebagai berikut :

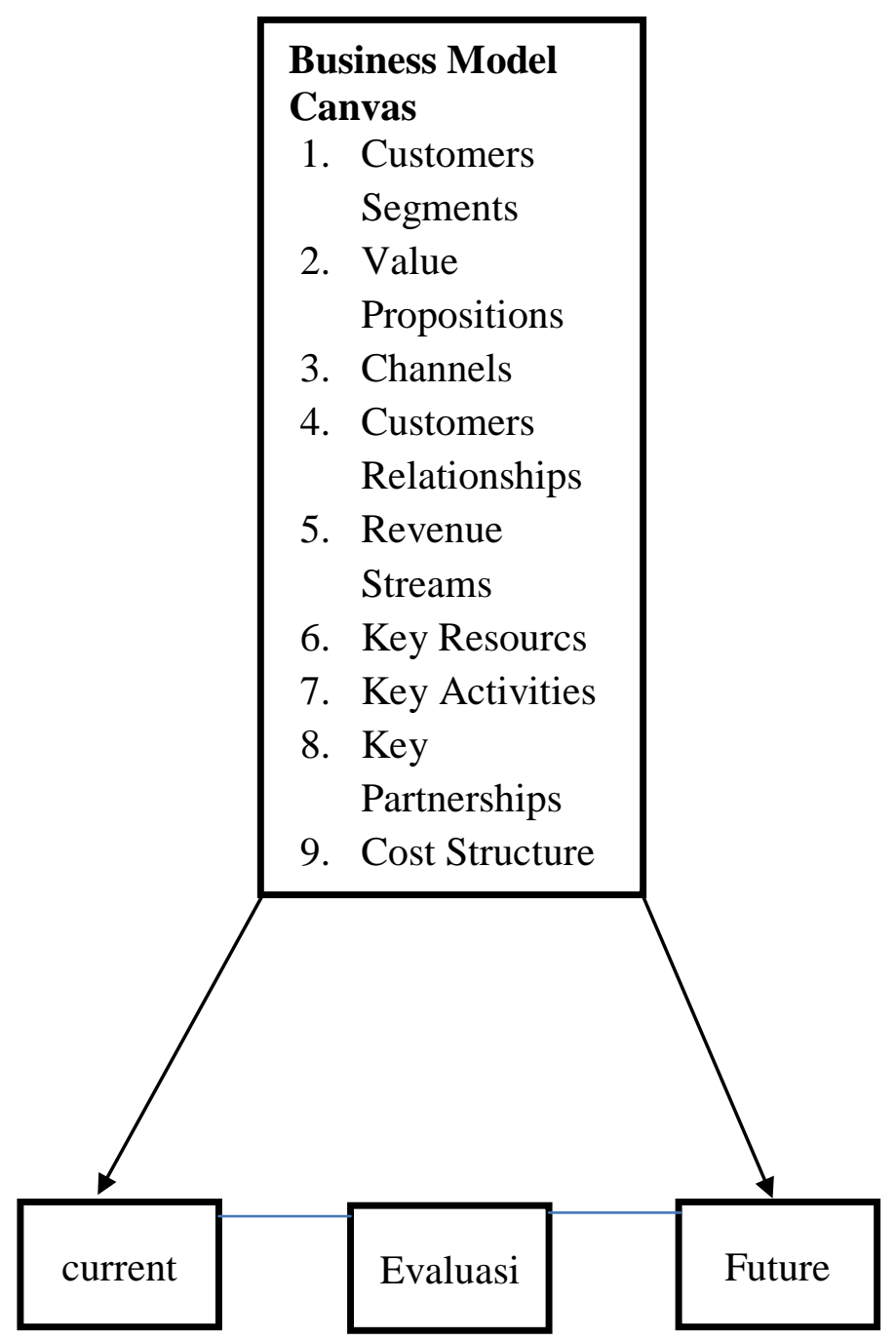

Sumber: Osterwalder dan pigneur ( 2009 )

\section{METODE}

Alasan pemilihan lokasi penelitian dengan pertimbangan teori menurut Moleong (2014:51) menentukan cara terbaik untuk ditempuh dengan jalan mempertimbangkan teori substantif dan menjajaki lapangan dan mencari kesesuaian dengan kenyataan yang ada di lapangan. Sementara itu keterbatasan geografi dan pertimbangan praktis seperti: waktu, biaya, tenaga perlu juga dijadikan pertimbangan dalam penentuan lokasi penelitian. Lokasi penelitian yang diambil dalam penelitian ini ditentukan dengan sengaja (purposive), penelitian ini dilakukan di Kabupaten Rokan Hulu dengan pertimbangan bahwa Kabupaten Rokan Hulu merupakan Kabupaten yang perkembangan pembangunan paling baik tetapi perkembangan UMKM yang termasuk lambat sehingga cocok dalam penelitian ini.

Fokus dalam penelitian ini adalah difokuskan pada penerapan Business model canvas di dalam penciptaan strategi bisnis untuk pengembangan usaha mikro kecil dan menengah.. Penentuan fokus penelitian lebih diarahkan pada tingkat kebaruan informasi yang akan diperoleh dari situasi sosial (lapangan) (Sugiyono, 2013).

Subjek penelitian ini adalah informan. Dalam penelitian ini informan dibagi menjadi dua yaitu: 1 . informan kunci (key informan), 2. informan pendukung. Informan kunci dalam penelitian ini adalah pemilik Usaha Mikro Kecil Dan Menengah (UMKM). Sedangkan informan pendukung adalah karyawan, Stakeholder dan konsumen. Penentuan informan dalam penelitian ini dilakukan snowball sampling. Alasan peneliti menggunakan teknik snowball sampling adalah dimana pada situasi tertentu, jumlah subjek penelitian yang terlibat menjadi bertambah, karena subjek atau informan penelitian yang telah ditentukan sebelumnya kurang memberikan informasi yang mendalam atau pada situasi tertentu tidak memungkinkan peneliti untuk mendapatkan akses pada sumber, lokasi atau subjek yang hendak diteliti. Adapun 
informan pada penelitian memiliki kriteria sebagai berikut:

1. Pemilik UMKM

2. Karyawan UMKM yang telah bekerja minimal selama satu tahun.

3. Konsumen yang telah membeli produk UMKM secara tetap atau secara continue.

4. Stakeholder yang berkaitan dengan UMKM seperti: supplier, mitra dan lain sebagainya.

5. Berusia antara 15-40 tahun sehat jasmani maupun rohani.

6. Dapat diajak berkomunikasi

7. Bersedia menjadi informan.

Teknik pengumpulan data merupakan langkah yang paling utama dalam penelitian, karena tujuan utama dari penelitian adalah untuk mendapatkan data. Penelitian ini menggunakan 3 metode dalam pengumpulan data yaitu:

1. Wawancara

2. Observasi

3. Dokumentasi

Untuk menggali informasi digunakan template Bussines Model Canvas dengan tiga tahap pengolahan data, seperti pada gambar berikut ini :

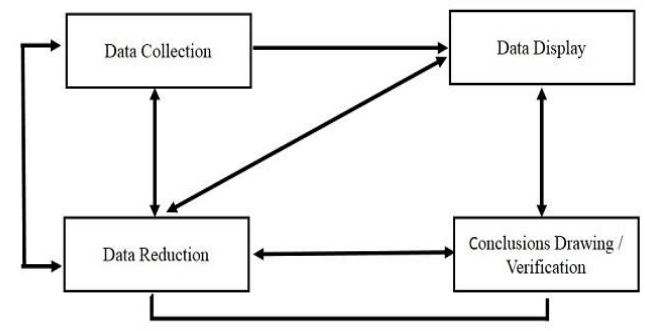

1. Data Reduction (Reduksi Data). Mereduksi data berarti merangkum, memilih hal-hal yang pokok, memfokuskan pada hal-hal yang penting, dicari tema dan polanya serta membuang yang tidak perlu. Data yang diperoleh dari lapangan jumlahnya cukup banyak, sehingga perlu dicatat secara teliti dan terperinci. Semakin lama peneliti turun kelapangan, maka jumlah data akan semakin banyak, kompleks dan rumit. Untuk itu perlu segera dilakukan analisis data melalui reduksi data. Yang bertujuan untuk memilih, merangkum serta memfokuskan terhadap data penting yang kita inginkan.

2. Data Display (Penyajian Data). Setelah data direduksi, maka langkah selanjutnya adalah mendisplay data. Tujuan mendisplay data yaitu untuk memudahkan dan memahami apa yang terjadi, serta merencanakan kerja selanjutnya berdasarkan apa yang dipahami. Selain itu mendisplay data juga untuk mempermudah peneliti dalam melihat gambaran secara keseluruhan atau bagian tertentu dari penelitian. Dalam penelitian ini penyajian data akan di tampilkan menggunakan template Bussines Model Canvas dengan Canvanizer 2.0

3. Conclusion Drawing / Verification (Penarikan Kesimpulan). Penarikan kesimpulan dilakukan untuk memverifikasi secara terusmenerus sepanjang proses penelitian berlangsung, yaitu selama proses pengumpulan data. Dalam penelitian yang dilakukan ini, penarikan kesimpulan dilakukan dengan pengambilan intisari dari rangkaian kategori hasil penelitian berdasarkan wawancara, observasi, dan dokumentasi. Yang mana peneliti ingin mengetahui pola hubungan, tema, serta hal-hal yang sering timbul, hipotesis dan sebagainya yang dituangkan dalam kesimpulan.

\section{HASIL}

Penelitian akan membahas tentang hasil wawancara dengan UMKM yang ada di Kabupaten Rokan Hulu yaitu tentang deskripsi 9 elemen Business Model Canvas ( BMC ). 


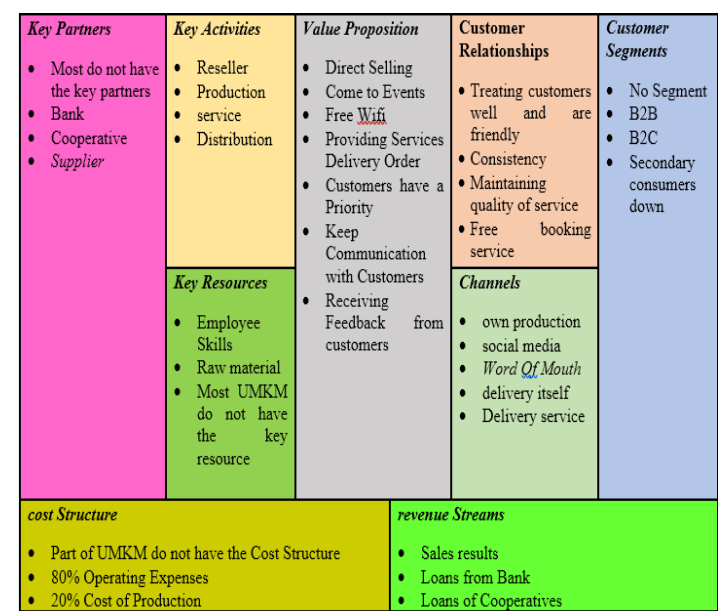

Sumber : Pengolahan Data primer, 2017

\section{Key Partnerships}

Key partnerships merupakan pihak yang menjalin hubungan kerja sama dengan pelaku usaha. Pemilik usaha yang ada di Rokan Hulu memiliki partner yang potensial seperti supplier dan customer yang dapat membantu owner dalam mencapai tujuannya. Selain itu, partner yang dimiliki oleh sebagian UMKM saat ini berpotensi untuk memiliki hubungan dalam jangka Panjang serta memiliki kemampuan untuk mengambangkan usaha dalam segi pendanaan.

\section{Key Activities}

Key Activities dalam dunia usaha sangat memberikan dampak yang baik dalam mengembangkan usaha. Pemilik usaha mengambil tindakan tersebut agar operasional berhasil. Beberapa UMKM yang ada di Rokan Hulu melakukan aktivitas produksi, distribusi kepada customer dan menjual kembali produk kepada konsumen.

\section{Value Propositions}

Value propositions yaitu nilai yang ingin diberikan oleh sebuah bisnis kepada customer segmentsnya. Perspektif dari value pada UMKM di Rokan Hulu ditemukan tidak hanya profit oriented di mana hanya mementingkan profit saja namun juga kualitas, komunikasi, service dan hubungan yang baik dengan customer. Dilihat dari elemen yang terdapat pada value propositions yaitu : direct selling, mendatangi event-event, menyedia free wifi, memberikan pelayanan order delivery, memiliki pelanggan prioritas, menjada komunikasi dengan pelanggan, menerima feedback dari pelanggan. artinya umkm di rokan hulu sudah berupaya untuk menjaga usaha meraka tetap eksis.

\section{Customer Relationships}

Customer relationships merupakan jenis hubungan yang ingin dibangun oleh pengusaha dengan masing-masing customer segments tertentu. UMKM yang terdapat di Rokan Hulu berusaha semaksimal mungkin untuk menjaga hubungan baik dengan customer. Dapat dikatakan pula bahwa kategori customer relationships yang diterapkan dalam UMKM di Rokan Hulu adalah berupaya memperlakukan konsumen dengan baik dan ramah, berusaha menjaga konsistensi usaha dalam produksi dan kualitas produk, Menjaga kualitas pelayanan kepada konsumen dan berusaha memberikan kecepatan pelayanan pemesanan

\section{Customer Segments}

Customer segments yaitu segmen pelanggan yang menjadi target sebuah bisnis. Adapun target market pada UMKM di Rokan Hulu yaitu lebih ke segment konsumen pada pendapatan menengah ke bawah. Dan ditemukan juga beberapa UMKM tidak memiliki segmen, yang artinya memiliki segmen pasr yang sangat luas. Semua UMKM di Rokan Hulu bergerak pada bisnis $\mathrm{B} 2 \mathrm{~B}$ dan $\mathrm{B} 2 \mathrm{C}$.

\section{Channel}

perusahaan

Channel merupakan cara menjangkau/berkomunikasi dengan pelanggan. UMKM di Rokan Hulu menjangkau customer secara direct (channels sendiri) dan indirect (partner channels). Proses usaha yang di lakukan oleh UMKM adalah memanfaatkan kemampuan produksi sendiri serta membangun saluran dengan memanfaatkan media social dan word of mouth. Serta beberapa UMKM telah membangun saluran 
dengan bekerja sama dengan beberapa jasa pengiriman yang ada di Rokan Hulu.

\section{Key Resources}

Key resources merupakan sumber daya perusahaan yang dibutuhkan perusahaan dalam membuat dan menawarkan value proposition, meraih pasar, menjaga hubungan dengan customer segments dan memperoleh pendapatan. Key resources pada UMKM di Rokan Hulu dapat dilihat dari 2 elemen yaitu physical( bahan baku) dan human (karyawan), sedangkan sebagian UMKM tidak memiliki kejelasan Key resources.

\section{Cost Structure}

Cost structure yaitu semua biaya yang dikeluarkan oleh perusahaan/usaha. Pada dasarnya UMKM di Rokan Hulu telah berupaya menyeimbangkan antara biaya tetap dan operasional yang meliputi dari biaya perlengkapan, biaya peralatan, biaya bensin, biaya gaji karyawan, biaya sewa ruko dan biaya kirim. Karakteristik cost structure UMKM di Rokan Hulu terbagi menjadi 4 yaitu fixed costs, variable costs, economies of scale serta economies of scope. Proporsi pembiayaan lebih besar di biaya operasional usaha yaitu sebesar $80 \%$ dari modal serta $20 \%$ untuk pembiayaan produksi. Ditemukan juga di UMKM di Rokan Hulu tidak memiliki cost structure karena minimnya keahlian dalam pelaporan keuangan.

\section{Revenue Streams}

Revenue streams merupakan pendapatan yang diperoleh perusahaan dari customer segments. UMKM di Rokan Hulu memperoleh pendapatan dari penjualan produk dengan mekanismi keuntungan dari harga jual yang telah di tambahkan estimasi keuntungan yang di inginkan serta mendapatkan suntikan pendanaan dari pihak ketiga yaitu koperasi ( Bumdes ) dan Bank.

\section{ANALISIS SWOT}

Analisa SWOT mendeskripsikan tentang strengths, weakness, opportunity dan threats dari UMKM yang ada di Rokan Hulu memiliki strengths dalam hal value propositions (harga terjangkau, kualitas bagus, Segment konsumen yang jelas, keseimbangan antara profit dan kualitas) dan key partnerships (hubungan dengan customer, supplier cukup baik). Sedangkan weakness dalam hal channel (Beberapa UMKM hanya mengandalkan konsumen datang), revenue streams (hanya memiliki 1 sumber pendapatan), key resources (kinerja karyawan rendah), key partnerships (hanya memiliki 1 supplier) dan cost structure (fixed costs besar). Opportunity yang dimiliki yaitu Pelaku Usaha sudah memanfaatkan media social, Geliat ekonomi masyarakat di Rokan Hulu mulai meningkat, Mayoritas UMKM di Rokan Hulu dalam tahap membangun semua. Threats yang ada yaitu perbedaan selera customer dan banyaknya pesaing dalam dunia bisnis yang sama.

\begin{tabular}{|c|c|}
\hline Strengths & Weakness \\
\hline Affordable prices & $\begin{array}{l}\text { Some UMKM rely on the consumer to } \\
\text { come }\end{array}$ \\
\hline Good quality & Revenue only comes from one source \\
\hline Relationship with customers, suppliers fairly good & Low employee performance \\
\hline Clear consumer segment & Supplier owned by only one person \\
\hline $\begin{array}{l}\text { Having a strong business and a balanced focus } \\
\text { between profit and quality }\end{array}$ & fixed costs large enough \\
\hline opportunity & Threats \\
\hline $\begin{array}{l}\text { Economic stretching society in Rokan Hulu Start } \\
\text { Rising }\end{array}$ & Customer tastes different \\
\hline $\begin{array}{l}\text { The majority of UMKM in Rokan Hulu in the } \\
\text { stage of building all } \\
\text { Business communities are already utilizing social } \\
\text { media }\end{array}$ & $\begin{array}{l}\text { Sufficient number of competitors in the } \\
\text { same business world }\end{array}$ \\
\hline
\end{tabular}

Sumber : Pengolahan Data primer, 2017

\section{PEMBAHASAN}

Blueocean Dan Strategi Oleh Business Model Canvas

\section{Customer Segments}

UMKM di Rokan Hulu harus mengembangkan customer segmentsnya yang lebih terfokus dan menggarap segment online store atau meningkatkan penggunaan media social. 


\section{Value Propositions}

UMKM di Rokan Hulu hendaknya meningkatkan value propositions yang ada saat ini. UMKM di Rokan Hulu bisa menjual dan memproduksi produk yang dibutuhkan oleh konsumen dengan mempertimbangkan trend yang berkermbang.

\section{Channels}

UMKM di Rokan Hulu harus dapat mengembangkan jangkauan melalui channel sendiri UMKM di Rokan Hulu dapat tetap mempertahankan apa yang ada saat ini.

\section{Customer Relationships}

Pada elemen ini, UMKM di Rokan Hulu dapat tetap mempertahankan fungsi customer relationshipsnya. UMKM di Rokan Hulu dapat mengembangkan kategori customer relationships menjadi self service (menggunakan sistem online).

\section{Revenue Streams}

UMKM di Rokan Hulu harus mampu menambah penghasilan dengan memanfaatka peluang yang ada misalnya dengan system franchise. Sedangkan untuk yang saat, pemililk UMKM harus berhati-hati dalam penggunaan modal karena sebagian besar pemilik usaha modal berasal dari pinjaman bank.

\section{Key Resources}

Key resources yang dapat dikembangkan oleh UMKM di Rokan Hulu misalnya memberikan pelatihan kepada karyawan.

\section{Key Activities}

Aktivitas yang dilakukan oleh UMKM di Rokan Hulu yaitu menetapkan customer segments yang baru, merencanakan konsep yang akan dikembangkan, mengimplementasikannya, serta menemukan strategi yang cocok pada setiap aktivitas usahanya. Seperti menggabungkan aktivitas reseller dan distribusi.

\section{Key Partnerships}

UMKM di Rokan Hulu dapat menambah supplier menjadi 2 atau 3 orang. Dari segi customer, sebaiknya UMKM di Rokan Hulu dapat memberikan kekhususan kepada customer yang menjadi resellernya ataupun pembeli borongan, misalnya dengan memberikan diskon ataupun membuat kartu member agar customer tersebut merasa lebih eksklusif.

\section{Cost Structure}

UMKM di Rokan Hulu perlu untuk mengurangi fixed costs yaitu biaya sewa toko dan biaya gaji karyawan.serta harus ada pelaporan kinerja keuangan pada setiap usaha,misalnnya laporan neraca, rugi laba dan arus kas.

\section{SIMPULAN}

Berdasarkan Penelitian ini, penulis dapat memberika beberapa kesimpulan diantaranya adalah Model Bisnis UMKM yang ada di Rokan Hulu secara garis besar masih tergolong masih tradisonal dimana kesembilan blok elemen utama dari Business Model Canvas terisi sedikit informasi. Serta dilapangan ditemukan beberapa pengusaha UMKM tidak mau memberikan informasi mengenai usahanya, hal ini memberika arti bahwa UMKM tersebut belum mampu untuk bersaing dengan competitor lainnya. Sudah seharusnya pembaharuan dilakukan pada Usaha UKM pada model bisnisnya di seluruh elemen. Segmentasi pasar misalnya sudah mulai penentuan segmentasi seperti demografis, psikologis, geografis yang berbeda dari sebelumnya. Pada penelitian ini memiliki keterbatasan yaitu UMKM yang di wawancarai tidak sepenuhnya memberikan informasi yang mendalam.

Ruang lingkup penelitian hanya di lakukan di pusat kota yang ada di Rokan Hulu yaitu Ujungbatu dan Pasir Pengaraian sebanyak 16 UMKM dengan kriteria omset yang besar dari 5 Juta keatas. Metode business model canvas memberikan kemudahan dalam mengidentifikasi secara jelas terhadap suatu strategi yang dimiliki oleh perusahaan atau UMKM. Hasil penelitian menunjukkan beberapa kelemahan dan kekuatan yang dimiliki UMKM yang ada di Rokan Hulu. Saran yang dapat penulis berikan yaitu bahwa metode business model canvas sangat kami anjurkan kepada pemilik usaha UMKM yang ada di Rokan Hulu untuk digunakan dalam melakukan pengambangan strategi 
usaha jangka panjang agar usaha semakin berkembang. Setiap UMKM harus memiliki visi untuk pengembangan usaha di masa akan datang. Penelitian yang akan datang dapat menggunakan sampel dan wilayah yang lebih luas

\section{DAFTAR RUJUKAN}

Boedianto, Laurentia Priska dan Harjati, Dhyah. $2015 . \quad$ Strategi Pengembangan Bisnis Pada Depot Selaris Dengan Pendekatan Business Model Canvas. Jurnal Universitas Petra. Surabaya.

Boone, Louis E. Kurtz, David L. 2008. Pengantar Bisnis Kontemporer, buku 1. Jakarta: Salemba Empat.

Bradford, Robert W., Duncan, Peter J., Tarcy, Brian, Simplified Strategic Planning: A No- Nonsense Guide for Busy People Who Want Results Fast, [Online] Available: http://www.QuickMBA.com/Strateg y/SWOTAnalysis [2016 mei 2016]

Dewobroto, Wisnu Sakti. 2013. Penggunaan Bussines Model Canvas sebagai Dasar Untuk Menciptakan Alternatif Strategi Bisnis dan Kelayakan Usaha. Jurnal Universitas Trisakti. Jakarta.

Dhewanto dkk. 2015. Manajemen Inovasi Untuk Usaha Kecil dan Mikro. Alfabeta. Bandung.

Moleong, Lexy J. 2014. Metode Penelitian Kualitatif. Remaja Rosdakarya. Bandung.

Osterwalder, Alexander dan Yves Pigneur. 2012. Business Model Gneration. PT Elex Media Komputindo. Jakarta.

Pearce dan Robinson, 2007, Manajemen Strategi, Salemba Empat, Jakarta
Putri, F.F.T. (2015). Analisis Inovasi Model Bisnis Menggunakan Pendekatan Busines Model Canvas. Jurnal Universitas Telkom. Bandung.

Stefan, Slavik dan Richard Bednar. 2014. Analysis of Business Model. Journal of Competitiveness. University of Economics in Bratislava.

Sugiyono. 2013. Metode Penelitian Bisnis. Alfabeta. Bandung.

Thompson, (2008), Crafting \& Executing Strategy; The Quest for Competitive advantage, sixteenth edition, McGraw-Hill International Edition.

Tjitradi, Elizabeth Cindy. 2015. Evaluasi dan Perancangan Model Bisnis berdasarkan Bussines Model Bisnis. Jurnal Universitas Petra. Surabaya

Undang-Undang Republik Indonesia Nomor 20 Tahun 2008 Tentang Usaha Mikro, Kecil, dan Menengah 